\title{
Correction to: The expression of ELOVL4, repressed by MYCN, defines neuroblastoma patients with good outcome
}

\author{
Francesco Rugolo (D), Nicolas G. Bazan (iD, Jorgelina Calandria (D), Bokkyoo Jun, Giuseppe Raschellà (iD, Gerry Melino (iD) and \\ Massimiliano Agostini (iD \\ (c) The Author(s), under exclusive licence to Springer Nature Limited 2021
}

Oncogene (2022) 41:1386-1387; https://doi.org/10.1038/s41388-021-02164-y

Correction to: Oncogene 2021;40:5741-51 https://doi.org/10.1038/ s41388-021-01959-3, published online 31 July 2021
In Fig. 1 of this article in panel B inserted the same micrograph in both control group (scramble and siELOVL4) was inserted; the Fig. 1 should have appeared as shown below.

The original article has been revised. 
A
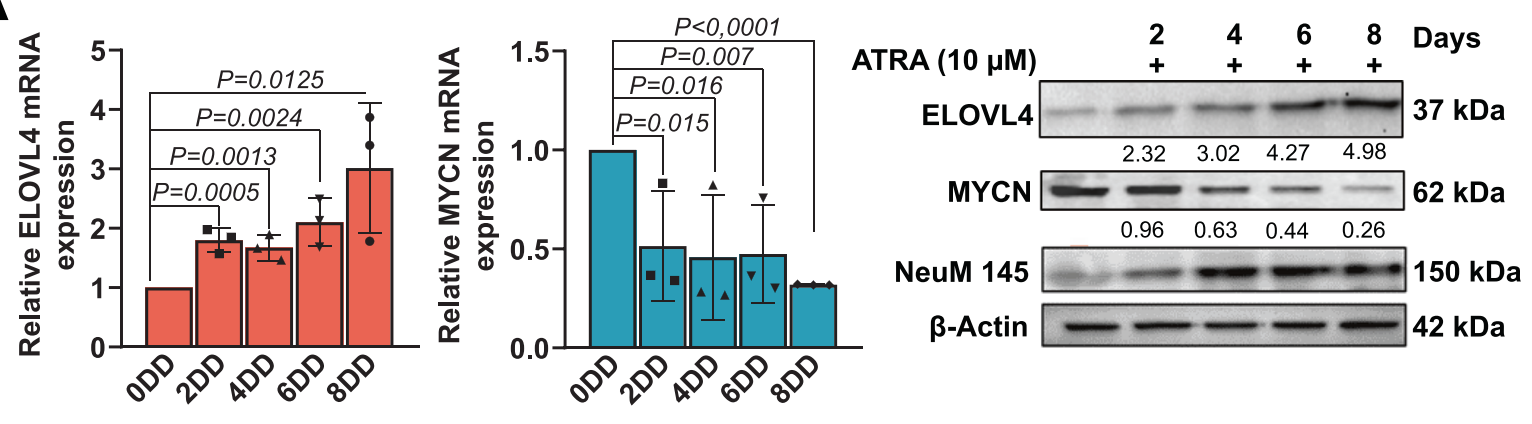

B

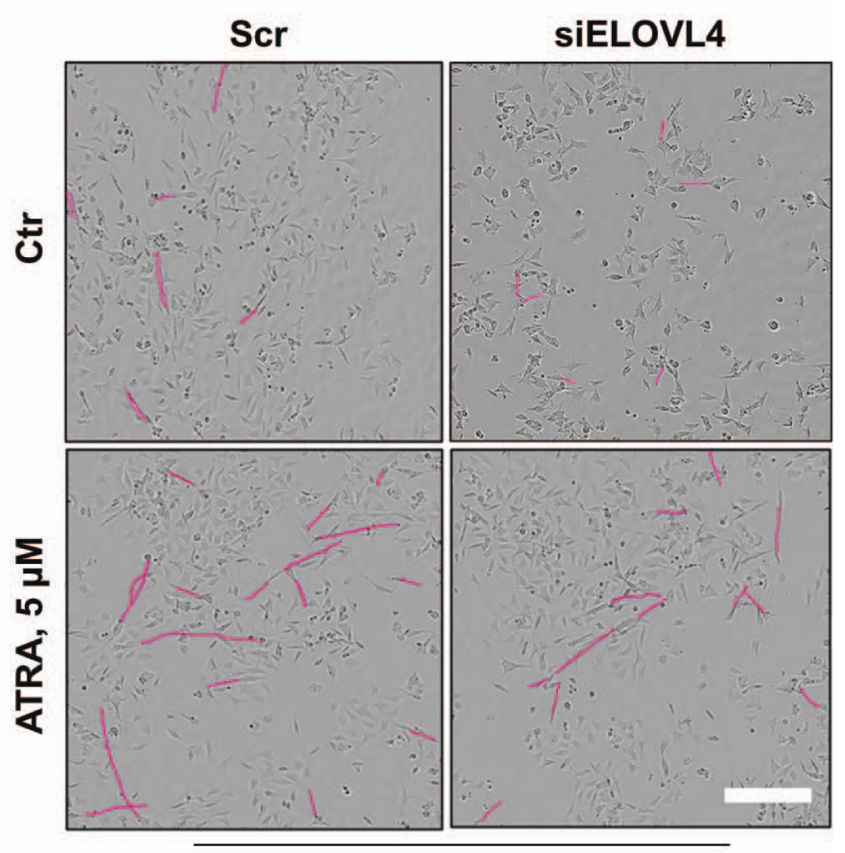

C
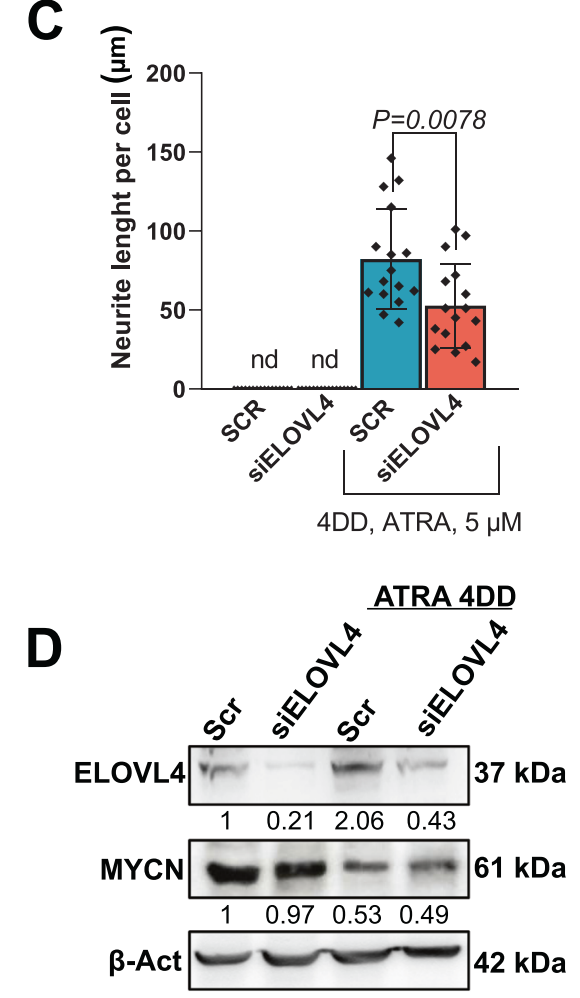

E
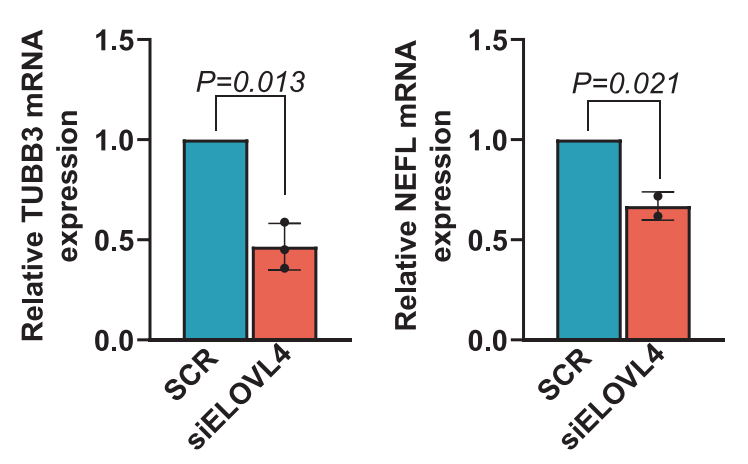

F
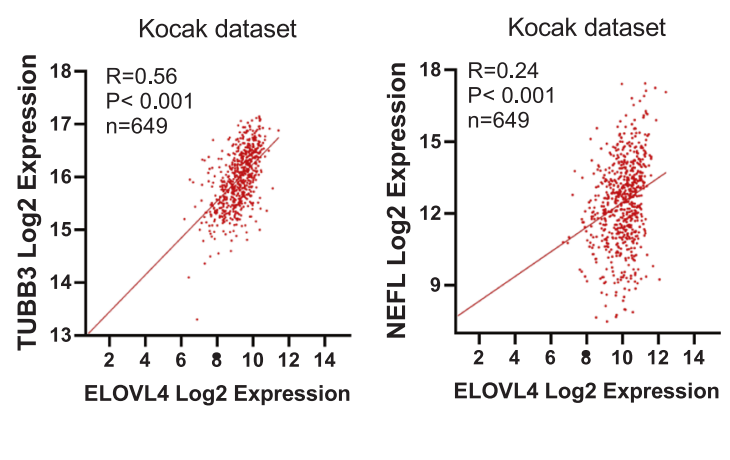